\title{
Prevalence of diarrhoeagenic Escherichia coli in children from León, Nicaragua
}

\begin{abstract}
Correspondence
Andrej Weintraub

Andrej.weintraub@ki.se
\end{abstract}

Received 16 October 2008

Accepted 16 January 2009

\author{
Samuel Vilchez, ${ }^{1,2}$ Daniel Reyes, ${ }^{1,3}$ Margarita Paniagua, ${ }^{1,3}$ \\ Filemon Bucardo, ${ }^{1,3,4}$ Roland Möllby ${ }^{3}$ and Andrej Weintraub ${ }^{2}$
}

\author{
${ }^{1}$ Department of Microbiology, Faculty of Medical Sciences, National Autonomous University of \\ Nicaragua (UNAN), León, Nicaragua \\ ${ }^{2}$ Division of Clinical Microbiology, Department of Laboratory Medicine, Karolinska Institutet, \\ Karolinska University Hospital, S-141 86 Stockholm, Sweden \\ ${ }^{3}$ Department of Microbiology, Tumor and Cell Biology (MTC), Karolinska Institutet, S-171 77 Solna, \\ Stockholm, Sweden \\ ${ }^{4}$ Division of Molecular Virology, Medical Faculty, Linköping University, Linköping, Sweden
}

\begin{abstract}
Diarrhoeal disease is a public health problem worldwide, mostly affecting children in developing countries. In Nicaragua, diarrhoea is the second greatest cause of infant mortality. During the period March 2005 to September 2006, a total of 526 faecal samples from children aged 0-60 months (381 with and 145 without diarrhoea) from León, Nicaragua, were studied. In order to detect five different diarrhoeagenic Escherichia coli pathotypes simultaneously [enterotoxigenic $E$. coli (ETEC), enteroaggregative E. coli (EAEC), enteropathogenic E. coli (EPEC),

enterohaemorrhagic E. coli (EHEC) and enteroinvasive E. coli (EIEC)], a mixture of eight primer pairs was used in a single PCR. At least one diarrhoeagenic E. coli pathotype was detected in 205 samples $(53.8 \%)$ of the diarrhoea group and in 77 samples $(53.1 \%)$ in the non-diarrhoea group. ETEC was detected significantly more often in children with diarrhoea $(20.5 \%)$ than in children without diarrhoea (8.3\%) $(P=0.001)$. Atypical EPEC, EIEC and EAEC were detected with slightly lower frequencies in children with (16.0, 0.8 and $27.8 \%$, respectively) than in children without (20.7, 1.4 and $33.1 \%$, respectively) diarrhoea. EHEC was only detected in children with diarrhoea $(2.1 \%)$. In conclusion, ETEC continues to be an important agent associated with diarrhoea in children from León, Nicaragua. Although not very frequent, the only findings that were $100 \%$ associated with diarrhoea were ETEC estA (4.7\%) and EHEC (2.1\%). Nevertheless, EAEC and EPEC were also frequent pathotypes in the population under study. In children with severe diarrhoea, more than half had EAEC, ETEC or EPEC, and EAEC was the most prevalent pathotype.
\end{abstract}

\section{INTRODUCTION}

Diarrhoeal disease continues to be one of the foremost public health problems worldwide, with over 1.5 million deaths occurring each year, mostly in children under 5 years in developing countries (Bryce et al., 2005). From 1985 to the present, diarrhoea has continued to be the second most common cause of infant mortality in Nicaragua. In 2004, the Ministry of Health in Nicaragua reported that, among the total number of diarrhoea cases, $71 \%$ were in children younger than 5 years of age, with a mortality rate of 11 per 10000 inhabitants. However, the morbidity rate for children of less than 1 year and of

Abbreviations: DEC, diarrhoeagenic E. coli; EAEC, enteroaggregative $E$. coli; EHEC, enterohaemorrhagic E. coli; EIEC, enteroinvasive E. coli; EPEC, enteropathogenic E. coli; ETEC, enterotoxigenic E. coli.
1-4 years of age was 3058 and 1157 per 10000 inhabitants, respectively (MINSA-NIC, 2004).

A broad range of recognized micro-organisms such as viruses, parasites and bacteria are associated with diarrhoea. Among the bacteria, diarrhoeagenic Escherichia coli (DEC) are some of the most frequently detected pathogens worldwide. There are six pathotypes of DEC: enterotoxigenic E. coli (ETEC), enteroaggregative E. coli (EAEC), enteropathogenic E. coli (EPEC), enterohaemorrhagic $E$. coli (EHEC) or verocytotoxin-producing E. coli, enteroinvasive $E$. coli (EIEC) and diffusely adherent $E$. coli (Bischoff et al., 2005; Kaper et al., 2004; Matar et al., 2002; Nataro \& Kaper, 1998; Paniagua et al., 1997).

The identification of DEC types requires differentiation from non-pathogenic members of the human normal 
intestinal flora. Molecular identification and classification of DEC is based on the presence of different chromosomal and/or plasmid-encoded virulence genes that are absent in commensal E. coli. Moreover, the prevalence and other epidemiological features of these pathogens as causative agents of diarrhoea vary in the world from region to region, and even between and within countries in the same geographical area (Al-Gallas et al., 2007; Kaper et al., 2004; Nataro et al., 2006; Nguyen et al., 2005; Paniagua et al., 1997; Vernacchio et al., 2006). In Nicaragua, EPEC and ETEC have been investigated and associated with secretory diarrhoea among children younger than 6 years, with children less than 2 years being the most affected (Mayatepek et al., 1993; Paniagua et al., 1997). In a study by Mayatepek et al. (1993) carried out in Esteli (northern zone), EPEC was found to be significantly more frequent in children with diarrhoea $(16 \%)$ than in healthy children $(4 \%)$. Nevertheless, ETEC rates were not statistically significantly different ( $28 \%$ of cases and $16 \%$ of controls). However, in a study carried out in León (north-western pacific side) by Paniagua et al. (1997), ETEC was found in $38 \%$ of diarrhoeal episodes and in $19 \%$ of asymptomatic controls. Furthermore, the majority of these children had two to three episodes of ETEC during the first 18 months of life. These two studies clearly exemplify the differences in prevalence of two DEC types within the same country. In this study, we aimed to determine the relative prevalence of five DEC types in children younger than 5 years of age with and without diarrhoea in León, Nicaragua.

\section{METHODS}

Clinical specimens. Between March 2005 and September 2006, 526 stool samples from children who were younger than 60 months of age were investigated for DEC. This included 381 children with and 145 without diarrhoea attending four different health care centres and the main hospital in León. Information on some clinical and epidemiological features was obtained through questionnaires. Patients were enrolled in the study if they had diarrhoea, characterized by the occurrence of three or more loose, liquid or watery stools or at least one bloody loose stool in a $24 \mathrm{~h}$ period (WHO, 2000). Control subjects were healthy children with no history of diarrhoea for at least 1 month. The sample collection was performed with the consent of the children's parent or guardian, and was approved by the local bioethical committee of the Faculty of Medical Sciences, National Autonomous University of Nicaragua, León.

Severity was defined as follows: 1, mild, when the episode lasted no longer than 3 days without fever and vomiting and with good toleration of oral rehydration therapy at home; 2, moderate, episode duration of more than 3 days with fever and/or vomiting and with toleration of oral rehydration at a health care centre; and 3, severe, episode with fever and vomiting, requiring intravenous rehydration and needing hospitalization (WHO, 2000).

Microbiological tests. Stool samples collected in sterile plastic containers were transported at $4{ }^{\circ} \mathrm{C}$ to the Microbiology Department of the National Autonomous University of Nicaragua, where primary microbiological examinations were conducted. Samples were cultured on MacConkey agar for the selection of E. coli isolates and on other media, such as deoxycholate citrate agar (for the selection of Shigella and Salmonella), with overnight incubation at $37^{\circ} \mathrm{C}$. All samples were tested for E. coli, Shigella and Salmonella by colony morphology and conventional biochemical tests as described previously (Gillespie \& Hawkey, 2006). In addition, samples were analysed for the presence of Giardia lamblia, Entamoeba histolytica, Cryptosporidium and Trichuris trichiura using conventional microscopy and staining methods as described previously (Leiva et al., 2005; Tellez et al., 2003). The presence of rotavirus and norovirus was also investigated by ELISA and RT-PCR as described previously (Bucardo et al., 2007, 2008). For E. coli, a full loop from each cultured plate suspected of being E. coli was stored at $-70{ }^{\circ} \mathrm{C}$ in brain heart infusion broth containing $15 \%$ $(\mathrm{v} / \mathrm{v})$ glycerol for further analysis. All samples were sent to the Department of Laboratory Medicine, Karolinska University Hospital, Huddinge, Stockholm, Sweden, where further characterization was performed. Occurrences of DEC were the main focus of this study.

Multiplex PCR. All E. coli-positive samples were analysed essentially as described by Nguyen et al. (2005) with some modifications. A brief description is detailed below.

DNA templates for PCR. A smear of bacteria from the first area of a MacConkey plate was suspended in $1 \mathrm{ml}$ PBS to a density of a 4 McFarland standard $\left(1 \times 10^{9}-5 \times 10^{9}\right.$ bacteria $\left.\mathrm{ml}^{-1}\right)$. The bacterial suspension was boiled for $20 \mathrm{~min}$, followed by centrifugation at $2500 \mathrm{~g}$ for $10 \mathrm{~min}$ to pellet the cell debris. The supernatant was used for PCR.

Multiplex PCR assay. Two microlitres of the lysate from the reference strains ETEC ATCC 35401, EHEC ATCC 43890, EHEC ATCC 43889, EPEC ATCC 43887, EIEC ATCC 43893, EAEC strain 97R harbouring pCVD432 and the E. coli negative control ATCC 11775, and from E. coli-positive samples, was subjected to multiplex PCR with specific primers (Table 1) for detection of the following virulence markers: eaeA (structural gene for intimin of EHEC and EPEC), $b f p A$ (structural gene for the bundle-forming pilus of EPEC), $v t 1$ and/or $v t 2$ (verocytotoxin 1 and 2 of EHEC), eltB and/or estA (enterotoxins LT and ST of ETEC), ial (invasion-associated locus of the invasion plasmid found in EIEC and Shigella) and pCVD (the nucleotide sequence of the EcoRI-PstI DNA fragment of pCVD432 of EAEC). The primers used for amplification matched the corresponding sequences of the genes for EAEC, EHEC, EIEC, EPEC and ETEC in GenBank. The minimum criteria for determination of DEC were defined as follows: the presence of eltB and/or est $A$ for ETEC; the presence of $v t 1$ and/or $v t 2$ for EHEC (the additional presence of eaeA confirmed the detection of a typical EHEC isolate); the presence of $b f p A$ and eaeA for typical EPEC (but the presence of only eaeA for atypical EPEC); the presence of ial for EIEC and Shigella; and the presence of pCVD432 for EAEC. Additionally, to confirm the PCR analysis, amplicons were analysed by sequencing the forward and reverse strands (data not shown) and by taking another smear of the same area cultured on a fresh MacConkey plate to get separate colonies. After incubation at $37^{\circ} \mathrm{C}$ overnight, five to eight colonies with typical $E$. coli morphology were streaked onto fresh plates. Each colony was tested independently by PCR with a primer specific for a suspected DEC isolate from the multiplex PCR.

PCRs were performed in a $25 \mu$ reaction mixture with a pureTaq Ready-To-Go PCR Bead (GE Healthcare UK). Each reaction mixture consisted of $2 \mu \mathrm{l}$ bacterial lysate, $10 \mathrm{mM}$ Tris/ $\mathrm{HCl}$ ( $\mathrm{pH} 9.0$ ), $50 \mathrm{mM}$ $\mathrm{KCl}, 1.5 \mathrm{mM} \mathrm{MgCl} 2,200 \mu \mathrm{M}$ each dNTP, $2.5 \mathrm{U}$ pureTaq DNA polymerase and $0.2 \mu \mathrm{M}$ each primer (from Interactiva Biotechnologie $\mathrm{GmbH}$ ), except for primer VT1, which was used at a concentration of $0.4 \mu \mathrm{M}$ (determined as the optimal concentration after standardizing the PCR assay). PCR was carried out in a GeneAmp PCR system 9700 (Applied Biosystems) with the following thermocycling conditions: $96{ }^{\circ} \mathrm{C}$ for $4 \mathrm{~min} ; 35$ cycles of $94{ }^{\circ} \mathrm{C}$ for $30 \mathrm{~s}, 58{ }^{\circ} \mathrm{C}$ for $30 \mathrm{~s}$ and $72{ }^{\circ} \mathrm{C}$ for $1 \mathrm{~min}$; and a final $7 \mathrm{~min}$ extension at $72{ }^{\circ} \mathrm{C}$. PCR products $(10 \mu \mathrm{l})$ were evaluated on a $1.5 \%(\mathrm{w} / \mathrm{v})$ agarose gel (UltraPure Agarose; 
Table 1. Primers used in the multiplex PCR for the detection of DEC types

\begin{tabular}{|c|c|c|c|c|c|}
\hline DEC type & Target gene & Primer & Primer sequences $\left(5^{\prime} \rightarrow 3^{\prime}\right)$ & $\begin{array}{l}\text { Fragment size } \\
\qquad(b p)\end{array}$ & $\begin{array}{c}\text { GenBank accession } \\
\text { no. }\end{array}$ \\
\hline \multirow[t]{2}{*}{ ETEC } & eltB & LT & $\begin{array}{l}\text { TCTCTATGTGCATACGGAGC } \\
\text { CCATACTGATTGCCGCAAT }\end{array}$ & 322 & S60731 \\
\hline & est $A$ & ST & $\begin{array}{l}\text { GTCAAACCAGTA(G/A)GGTCTTCAAAA } \\
\text { CCCGGTACA(G/A)GGAGGATTACAACA }\end{array}$ & 147 & M34916 \\
\hline \multirow[t]{2}{*}{ EHEC } & $v t 1$ & VT1 & $\begin{array}{l}\text { GAAGAGTCCGTGGGATTAC } \\
\text { AGCGATGCAGCTATTAATAA }\end{array}$ & 130 & AF461172 \\
\hline & $v t 2$ & VT2 & $\begin{array}{l}\text { ACCGTTTTTCAGATTTT(G/A)CACATA } \\
\text { TACACAGGAGCAGTTTCAGACAGT }\end{array}$ & 298 & AY143337 \\
\hline \multirow[t]{2}{*}{ EPEC } & eaeA & eae & $\begin{array}{l}\text { CACACGAATAAACTGACTAAAATG } \\
\text { AAAAACGCTGACCCGCACCTAAAT }\end{array}$ & 376 & AE005595 \\
\hline & $b f p A$ & bfpA & $\begin{array}{l}\text { TTCTTGGTGCTTGCGTGTCTTTT } \\
\text { TTTTGTTTGTTGTATCTTTGTAA }\end{array}$ & 367 & U27184 \\
\hline EIEC & ial & SHIG & $\begin{array}{l}\text { CTGGTAGGTATGGTGAGG } \\
\text { CCAGGCCAACAATTATTTCC }\end{array}$ & 320 & AY167049 \\
\hline EAEC & pCVD432 & EA & $\begin{array}{l}\text { CTGGCGAAAGACTGTATCAT } \\
\text { AAATGTATAGAAATCCGCTGTT }\end{array}$ & 630 & X81423 \\
\hline
\end{tabular}

Invitrogen Life Technologies) at $120 \mathrm{mV}$ for $30 \mathrm{~min}$. A molecular marker (TrackIt 100 bp DNA Ladder; Invitrogen Life Technologies) was run concurrently. The DNA bands were visualized and photographed under UV light after the gel had been stained with ethidium bromide.

Data analysis. A $\chi^{2}$ test or Fisher's exact test was used to determine the statistical significance of the data. A $P$ value of $<0.05$ was considered significant.

\section{RESULTS AND DISCUSSION}

\section{Clinical specimens}

A total of 526 stool samples from 381 children with diarrhoea and 145 children without diarrhoea were collected. Among the total samples, 280 (53.2\%) children were younger than 12 months, 160 (30.4\%) were 13-24 months and 86 (16.4\%) were 25-60 months. The overall sex distribution was $320(60.8 \%)$ male and $206(39.2 \%)$ female.

\section{Detection of DEC}

In this study, in order to detect the five different categories of DEC simultaneously, a mixture of eight primer pairs specific for the target genes was used in a single PCR. Samples with each target sequence of the five different categories of DEC were tested by the multiplex PCR. Fig. 1 shows that the multiplex PCR could detect one or more DEC strains in a single sample. Due to close similarities in band sizes, it was difficult to distinguish individual bands in some cases; as a result, it was necessary to run a primerspecific PCR on single colonies to verify the detection of the suspected DEC isolate.

From the 526 samples, at least one DEC type was detected in $282(53.6 \%)$ of the samples. In the diarrhoea group, 205
(53.8\%) samples were positive, and $77(53.1 \%)$ were positive in the non-diarrhoea group. However, overall, 348 DEC were isolated from the 526 samples: 256 (67.2\%) were identified in the samples from children with diarrhoea, and $92(63.4 \%)$ in children without diarrhoea (Table 2). Forty-eight children (12.6\%) from the diarrhoea group and $15(10.3 \%)$ from the non-diarrhoea group were colonized with more than one DEC pathotype. EAEC was the most prevalent pathotype identified, followed by atypical EPEC (only eaeA), ETEC, EHEC and EIEC. No typical EPEC $(e a e A+b f p A)$ was detected in this study.

The ETEC pathotype was isolated significantly more often in children with $(20.5 \%)$ than in children without $(8.3 \%)$ diarrhoea $(P<0.001)$ (Table 2). Atypical EPEC, EIEC and EAEC were isolated with slightly lower frequencies in children with (16.0, 0.8 and $27.8 \%$, respectively) than in children without (20.7, 1.4 and $33.1 \%$, respectively) diarrhoea. EHEC was only detected in children with diarrhoea $(2.1 \%)$.

The ETEC pathotype was detected in all age groups, but a slightly higher prevalence was seen in children under 12 months of age (Table 3), where a significant difference $(P<0.001)$ in frequencies between children with and without diarrhoea was also seen. Atypical EPEC, EIEC, EHEC and EAEC were detected in all age groups, but no statistically significant differences were seen in any of the groups. Of the 78 ETEC strains isolated in the diarrhoea group, 60 were eltB, four were est $A$ and 14 were eltB/est $A$. ETEC was identified in 12 of the non-diarrhoea group children. However, these strains were positive only for elt $B$, a finding that clearly associates est $A(P=0.008)$ with diarrhoeal disease. Thus ETEC appears to cause secretory diarrhoea early in life, well before 1 year of age, after which a high carriage rate is seen.

In this study, isolation of one or more DEC types alone or in combination with another enteric pathogen or patho- 


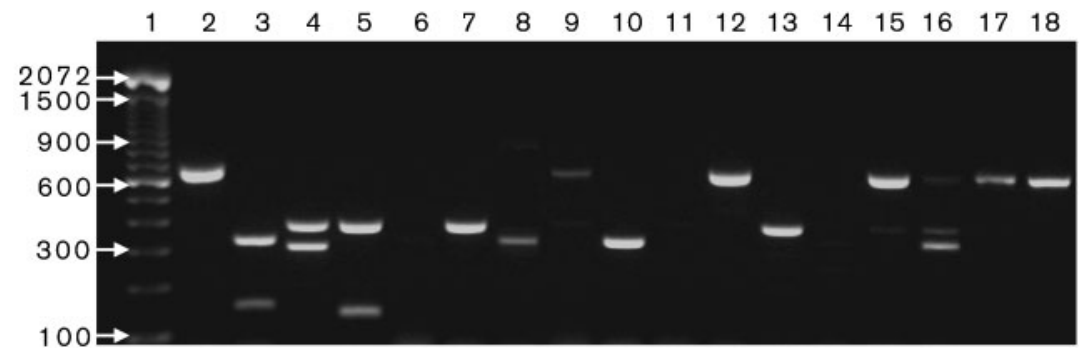

Fig. 1. Multiplex PCR amplification of reference strains and clinical samples of DEC. Lanes: 1, molecular marker (Tracklt $100 \mathrm{bp}$ DNA Ladder; Invitrogen Life Technologies); 2, EAEC 97R; 3, ETEC ATCC 35401; 4, EHEC ATCC 43889; 5, EHEC ATCC 43890; $6, E$. coli ATCC 11775; 7, EPEC ATCC 43887; 8 , EIEC ATCC 43893; 9-18, clinical samples. Numbers on the left denote fragment sizes (bp).

gens was common: $81(21.3 \%)$ and $16(11.0 \%)$ samples in the diarrhoea group and the non-diarrhoea group $(P=0.007)$, respectively (Table 4$)$. The most frequent combinations were EAEC + EPEC (3.9\%), EAEC + ETEC $(2.9 \%)$, EAEC + norovirus $(2.4 \%)$, ETEC + EPEC $(1.3 \%)$, ETEC + norovirus $(1.8 \%)$ and EPEC + norovirus $(1.3 \%)$. However, statistically significant differences were seen only for EAEC + norovirus co-infection $(P=0.05)$, and as an overall result.

Clinical symptoms from the children with diarrhoea such as fever, vomiting, nausea, loss of appetite, abdominal pain, stool properties and the number of episodes per day were recorded. In general, the frequencies of symptoms were similar regardless of the isolated DEC pathotype (Table 5). This suggests that, based on these clinical findings, an infection with, for example, ETEC could not be distinguished from an infection with atypical EPEC, EIEC, EAEC or EHEC.

The majority of the diarrhoeal cases were classified as mild (269; 70.6\%), followed by severe $(68 ; 17.9 \%)$ and moderate $(44 ; 11.5 \%)$. However, when a DEC type was identified, 139 cases $(67.8 \%)$ were mild, 42 (20.5\%) severe and $24(11.7 \%)$ moderate. Twenty-two EAEC (32.4\%) were identified in severe cases, followed by 19 ETEC (27.9\%) and 14 atypical EPEC (20.6\%), either alone or in combination (Table 5).

Our results highlight the importance of ETEC as a cause of childhood diarrhoea in the studied region of Nicaragua. Unlike a study in Vietnam (Nguyen et al., 2005), our study shows that the prevalence of ETEC in the diarrhoea group was significantly higher in children younger than 1 year of age than in older children, although ETEC was detected in all age groups. Additionally, our results support data from a previous prospective cohort study on the incidence of infection with ETEC in infants from Nicaragua, where it was shown that the highest incidence of ETEC diarrhoeal illness occurred during the first year of life (Paniagua et al., 1997).

EAEC is an emerging pathogen associated with diarrhoea. It has been identified in travellers, children in the developing world and human immunodeficiency virusinfected patients with diarrhoea (Adachi et al., 2002; Kaper et al., 2004; Keskimaki et al., 2000; Nguyen et al., 2005; Nishikawa et al., 2002). In the present study, EAEC strains were the most frequently isolated pathotype of $E$. coli; however, the isolation rate as a total was slightly higher in

Table 2. DEC among children with and without diarrhoea from León, Nicaragua

\begin{tabular}{|c|c|c|c|c|c|}
\hline \multirow[t]{2}{*}{ DEC type } & \multirow[t]{2}{*}{ PCR type } & \multicolumn{2}{|c|}{$\begin{array}{l}\text { No. (\%) of children with and without } \\
\text { diarrhoea }\end{array}$} & \multirow[t]{2}{*}{ Odds ratio $(95 \% \mathrm{CI})^{\star}$} & \multirow[t]{2}{*}{$P$ value $\left(\chi^{2}\right)$} \\
\hline & & $\begin{array}{l}\text { Diarrhoea group } \\
\qquad(n=381)\end{array}$ & $\begin{array}{l}\text { Non-diarrhoea group } \\
\qquad(n=145)\end{array}$ & & \\
\hline \multirow[t]{4}{*}{ ETEC } & All & $78(20.5)$ & $12(8.3)$ & $2.4(1.4-4.4)$ & 0.001 \\
\hline & eltB & $60(15.7)$ & $12(8.3)$ & $1.9(1.1-3.4)$ & 0.026 \\
\hline & estA & $4(1.0)$ & $0(0.0)$ & NA & 0.216 \\
\hline & eltB/est $A$ & $14(3.7)$ & $0(0.0)$ & NA & 0.019 \\
\hline Atypical EPEC & $e a e A$ & $61(16.0)$ & $30(20.7)$ & $0.7(0.5-1.1)$ & 0.205 \\
\hline EIEC & ial & $3(0.8)$ & $2(1.4)$ & NA & 0.532 \\
\hline EAEC & pCVD432 & $106(27.8)$ & $48(33.1)$ & $0.8(0.6-1.1)$ & 0.234 \\
\hline \multirow[t]{4}{*}{ EHEC } & All & $8(2.1)$ & $0(0.0)$ & NA & 0.079 \\
\hline & $v t 1$ & $1(0.3)$ & $0(0.0)$ & NA & 0.537 \\
\hline & $v t 2$ & $6(1.6)$ & $0(0.0)$ & $\mathrm{NA}$ & 0.129 \\
\hline & $v t 2 / e a e A$ & $1(0.3)$ & $0(0.0)$ & NA & 0.537 \\
\hline
\end{tabular}

${ }^{\star} \mathrm{CI}$, Confidence interval; NA, not applicable. 
Table 3. Prevalence of DEC among children less than 1 year of age

\begin{tabular}{|c|c|c|c|c|c|}
\hline \multirow[t]{2}{*}{ DEC type } & \multirow[t]{2}{*}{ PCR type } & \multicolumn{2}{|c|}{$\begin{array}{c}\text { No. (\%) of positive children } \\
(0-12 \text { months })\end{array}$} & \multirow[t]{2}{*}{ Odds ratio $(95 \% \mathrm{CI})^{*}$} & \multirow[t]{2}{*}{$P$ value $\left(\chi^{2}\right)$} \\
\hline & & $\begin{array}{l}\text { Diarrhoea group } \\
\qquad(n=192)\end{array}$ & $\begin{array}{c}\text { Non-diarrhoea } \\
\text { group }(n=88)\end{array}$ & & \\
\hline \multirow[t]{4}{*}{ ETEC } & All & $44(22.9)$ & $5(5.7)$ & $4.0(1.7-9.8)$ & $<0.0001$ \\
\hline & eltB & $36(18.8)$ & $5(5.7)$ & $3.3(1.3-8.1)$ & 0.03 \\
\hline & estA & $1(0.52)$ & $0(0.0)$ & NA & 0.498 \\
\hline & eltB/est $A$ & $7(3.6)$ & $0(0.0)$ & NA & 0.070 \\
\hline Atypical EPEC & $e a e A$ & $33(17.2)$ & $18(20.5)$ & $0.8(0.5-1.4)$ & 0.511 \\
\hline EIEC & ial & $2(1.0)$ & $1(1.1)$ & NA & 0.943 \\
\hline EAEC & pCVD432 & $64(33.3)$ & $29(33.0)$ & $1.1(0.7-1.5)$ & 0.950 \\
\hline \multirow[t]{4}{*}{ EHEC } & All & $1(0.5)$ & $0(0.0)$ & NA & 0.498 \\
\hline & $v t 1$ & $0(0.0)$ & $0(0.0)$ & NA & NA \\
\hline & $v t 2$ & $1(0.5)$ & $0(0.0)$ & NA & 0.498 \\
\hline & $v t 2 / e a e A$ & $0(0.0)$ & $0(0.0)$ & NA & NA \\
\hline
\end{tabular}

NA, Not applicable.

${ }^{\star} \mathrm{CI}$, Confidence interval.

Table 4. Frequency of co-infections when a DEC type was identified, among the diarrhoeal and non-diarrhoeal group

\begin{tabular}{|c|c|c|}
\hline \multirow[t]{2}{*}{ Diarrhoeagenic E. coli+diarrhoeal pathogen } & \multicolumn{2}{|c|}{ No. (\%) of positive samples } \\
\hline & Diarrhoea group $(n=381)$ & Non-diarrhoea group $(n=145)$ \\
\hline $\mathrm{EAEC}+\mathrm{aEPEC}$ & $15(3.9)$ & $11(7.6)$ \\
\hline EAEC + ETEC & $11(2.9)$ & $2(1.4)$ \\
\hline $\mathrm{ETEC}+\mathrm{aEPEC}$ & $5(1.3)$ & $0(0.0)$ \\
\hline $\mathrm{EAEC}+\mathrm{aEPEC}+\mathrm{ETEC}$ & $3(0.8)$ & $0(0.0)$ \\
\hline $\mathrm{EAEC}+\mathrm{EHEC}$ & $1(0.3)$ & $0(0.0)$ \\
\hline $\mathrm{aEPEC}+\mathrm{EHEC}$ & $1(0.3)$ & $0(0.0)$ \\
\hline ETEC + EIEC & $1(0.3)$ & $0(0.0)$ \\
\hline ETEC + Entamoeba histolytica & $1(0.3)$ & $0(0.0)$ \\
\hline ETEC + G. lamblia & $2(0.5)$ & $1(0.7)$ \\
\hline $\mathrm{aEPEC}+$ G. lamblia & $1(0.3)$ & $0(0.0)$ \\
\hline EAEC + G. lamblia & $2(0.5)$ & $0(0.0)$ \\
\hline EAEC $+\mathrm{aEPEC}+$ G. lamblia & $0(0.0)$ & $1(0.7)$ \\
\hline EAEC + ETEC + G. lamblia & $1(0.3)$ & $0(0.0)$ \\
\hline EAEC + EHEC + G. lamblia & $1(0.3)$ & $0(0.0)$ \\
\hline EAEC + aEPEC + Cryptosporidium & $0(0.0)$ & $1(0.7)$ \\
\hline EAEC $+T$. trichiura & $1(0.3)$ & $0(0.0)$ \\
\hline ETEC + norovirus & $7(1.8)$ & $0(0.0)$ \\
\hline EIEC + norovirus & $1(0.3)$ & $0(0.0)$ \\
\hline $\mathrm{aEPEC}+$ norovirus & $5(1.3)$ & $0(0.0)$ \\
\hline EAEC + norovirus & $9(2.4)$ & $0(0.0)^{*}$ \\
\hline EAEC $+\mathrm{aEPEC}+$ norovirus & $3(0.8)$ & $0(0.0)$ \\
\hline EAEC + ETEC + norovirus & $3(0.8)$ & $0(0.0)$ \\
\hline ETEC $+\mathrm{aEPEC}+$ norovirus & $2(0.5)$ & $0(0.0)$ \\
\hline EAEC + EHEC + norovirus & $1(0.3)$ & $0(0.0)$ \\
\hline $\mathrm{ETEC}+$ rotavirus & $1(0.3)$ & $0(0.0)$ \\
\hline aEPEC + rotavirus & $1(0.3)$ & $0(0.0)$ \\
\hline ETEC + Shigella spp. & $1(0.3)$ & $0(0.0)$ \\
\hline aEPEC + Shigella spp. & $1(0.3)$ & $0(0.0)$ \\
\hline Total & $81(21.3)$ & $16(11.0) \dagger$ \\
\hline
\end{tabular}

${ }^{\star} P<0.05$.

$\dagger P=0.007$. 
Table 5. Clinical symptoms in children with diarrhoea where a DEC pathotype was identified

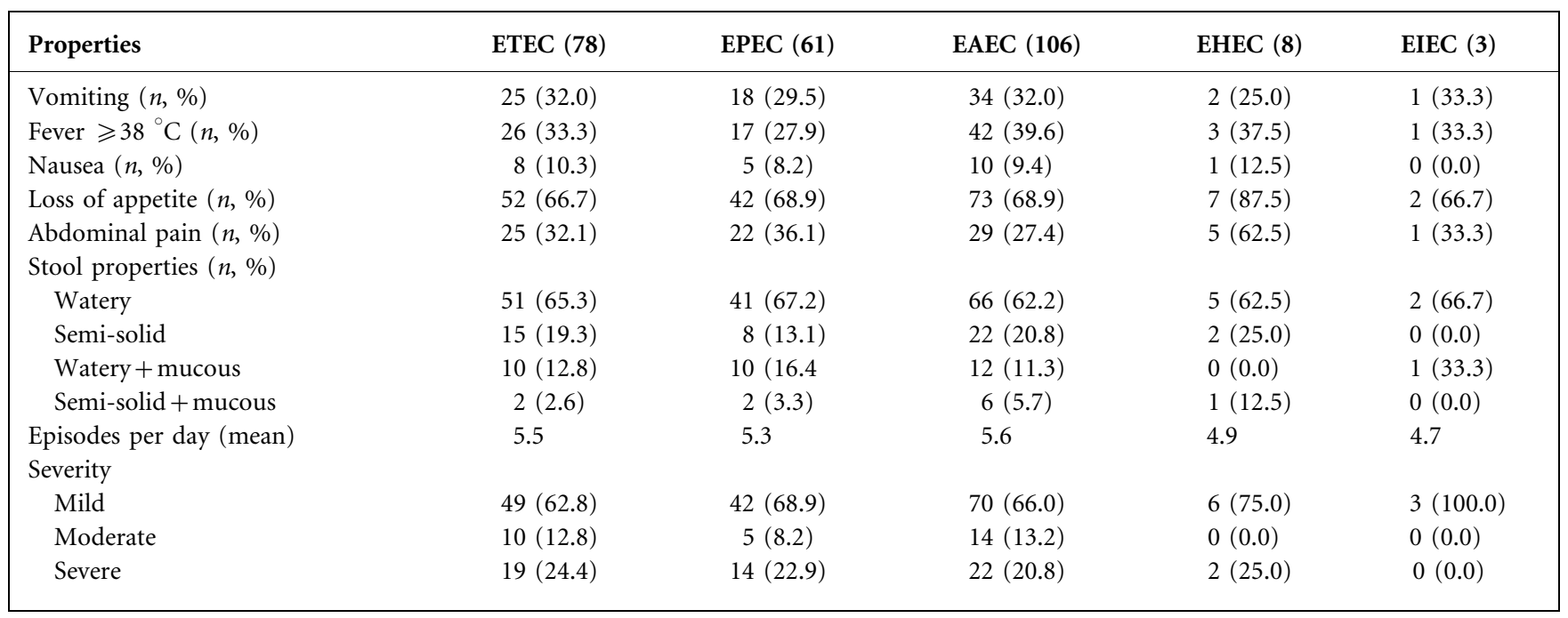

the non-diarrhoeal group than in the diarrhoeal group. An even higher isolation rate in the non-diarrhoeal group compared with the diarrhoeal group in children aged 12 24 (34.0 vs $23.3 \%$ ) and $25-60$ (34.0 vs $20.5 \%)$ months was correspondingly seen (data not shown). However, in children less than 1 year of age, similar isolation rates were observed in the diarrhoea $(33.3 \%)$ versus the nondiarrhoea $(33.0 \%)$ group (Table 3 ). These observations are not in disagreement with other studies where EAEC was isolated at higher frequency rates from controls than from children with diarrhoea (Spano et al., 2008; Vernacchio et al., 2006). However, in other studies carried out in children in Vietnam and the USA, EAEC was isolated at higher prevalence in cases ( 11.6 and $4.5 \%$, respectively) than in controls (7.2 and $1.7 \%$, respectively) (Nataro et al., 2006; Nguyen et al., 2005). The fact that EAEC was not statistically associated with diarrhoea in the present study, even though it was the most dominant pathotype isolated from the severe cases, followed by ETEC and EPEC, could be due to a high level of asymptomatic carriers. This lack of association with diarrhoea has been observed in another study and with other well-established enteropathogens (Gomes et al., 1991). It has also been shown that EAEC is a heterogeneous group of E. coli (Czeczulin et al., 1999; Jenkins et al., 2007) and not all strains are capable of causing diarrhoea. Furthermore, the DNA probe used in this study to detect EAEC was a derivate from the pAA plasmid, and does not discriminate between true virulent strains. A need for future characterization of these EAEC strains is required involving a more detailed molecular characterization of the different putative virulence genes in order to determine their actual role in the studied population (Czeczulin et al., 1999; Jenkins et al., 2006, 2007; Jiang et al., 2003).

EPEC is also a very important pathogen in children with diarrhoea. EPEC infection is primarily a disease of infants younger than 2 years of age. Numerous case-control studies in many countries have found that EPEC is more frequently isolated from children with diarrhoea than from healthy controls (Kaper et al., 2004; Nataro \& Kaper, 1998). In a study carried out in a northern city of Nicaragua, EPEC was found to be significantly more frequent in diarrhoeal $(16 \%)$ than in healthy $(4 \%)$ children (Mayatepek et al., 1993). However, in our study, the isolation rate of EPEC strains from children with diarrhoea was slightly lower than that from children without diarrhoea. This finding has also been seen in another study, where this pathotype was recovered more frequently from non-diarrhoeal cases than from diarrhoeal cases (Echeverria et al., 1989). Our findings highlight the variation in prevalence of one DEC type (EPEC) as a causative agent of diarrhoea within the same country. Additionally, the role of atypical EPEC in diarrhoea has not been established decisively (Kaper et al., 2004; Nataro \& Kaper, 1998; Nataro et al., 2006), and this study did not demonstrate a diarrhoeagenic role for this pathotype.

EPEC and EHEC share eaeA (the intimin structural gene), but the major virulence factors defining the characteristics of EHEC are the verocytotoxins. In the present study, we identified a few EHEC strains from children with diarrhoea, but none from children without. These results agree with the low prevalence of EHEC infection in developing countries (Brown et al., 1989; Strockbine et al., 1992). It is also evident that the carrier rates of these pathogens are very low $(<1 \%)$.

The low frequencies of EHEC and EIEC strains in the studied population were, in general, in agreement with other studies performed in different parts of the world (Gomes et al., 1991; Nguyen et al., 2005).

In conclusion, ETEC continues to be an important agent associated with diarrhoea in children from León, Nicaragua, as reported previously, and the carriage rate of estA (the gene for ST) is below $5 \%$. EAEC and EPEC, on the other hand, were recovered at high rates from children with and without diarrhoea, indicating a wide spread of 
these pathotypes in the study population and a high carriage rate after primary infection. Additionally, more than half of the children with severe diarrhoea carried EAEC, ETEC or EPEC.

\section{ACKNOWLEDGEMENTS}

This work was supported by grants from the Swedish Agency for Research Cooperation with Developing Countries and the National Autonomous University of Nicaragua, León. We thank the children and their parents for kindly providing the stool samples. We also thank Patricia Blandón and Soledad Calderón for their valuable technical assistance, and the nurses and paediatricians for their help in sample collection and transportation, especially Doña Silvia. We also thank Patricia Colque-Navarro and Inger Kühn for their valuable input into this study.

\section{REFERENCES}

Adachi, J. A., Ericsson, C. D., Jiang, Z. D., DuPont, M. W., Pallegar, S. R. \& DuPont, H. L. (2002). Natural history of enteroaggregative and enterotoxigenic Escherichia coli infection among US travelers to Guadalajara, Mexico. J Infect Dis 185, 1681-1683.

Al-Gallas, N., Bahri, O., Bouratbeen, A., Ben Haasen, A. \& Ben Aissa, R. (2007). Etiology of acute diarrhea in children and adults in Tunis, Tunisia, with emphasis on diarrheagenic Escherichia coli: prevalence, phenotyping, and molecular epidemiology. Am J Trop Med Hyg 77, 571-582.

Bischoff, C., Luthy, J., Altwegg, M. \& Baggi, F. (2005). Rapid detection of diarrheagenic E. coli by real-time PCR. J Microbiol Methods 61, 335-341.

Brown, J. E., Echeverria, P., Taylor, D. N., Seriwatana, J., Vanapruks, V., Lexomboon, U., Neill, R. N. \& Newland, J. W. (1989). Determination by DNA hybridization of Shiga-like-toxin-producing Escherichia coli in children with diarrhea in Thailand. J Clin Microbiol 27, 291-294.

Bryce, J., Boschi-Pinto, C., Shibuya, K. \& Black, R.WHO Child Health Epidemiology Reference Group (2005). WHO estimates of the causes of death in children. Lancet 365, 1147-1152.

Bucardo, F., Karlsson, B., Nordgren, J., Paniagua, M., González, A., Amador, J. J., Espinoza, F. \& Svensson, L. (2007). Mutated G4P[8] rotavirus associated with a nationwide outbreak of gastroenteritis in Nicaragua 2005. J Clin Microbiol 45, 990-997.

Bucardo, F., Nordgren, J., Carlsson, B., Paniagua, M., Lindgren, P.-E., Espinoza, F. \& Svensson, L. (2008). Pediatric norovirus diarrhea in Nicaragua. J Clin Microbiol 46, 2573-2580.

Czeczulin, J. R., Whittam, T. S., Henderson, I. R., Navarro-Garcia, F. \& Nataro, J. P. (1999). Phylogenetic analysis of enteroaggregative and diffusely adherent Escherichia coli. Infect Immun 67, 2692-2699.

Echeverria, P., Taylor, D. N., Lexsomboon, U., Bhaibulaya, M., Blacklow, N. R., Tamura, K. \& Sakazaki, R. (1989). Case-control study of endemic diarrheal disease in Thai children. J Infect Dis 159, 543-548.

Gillespie, S. H. \& Hawkey, P. M. (2006). Principles and Practice of Clinical Bacteriology, 2nd edn. Chichester: John Wiley \& Sons.

Gomes, T. A., Rassi, V., MacDonald, K. L., Ramos, S. R., Trabulsi, L. R., Vieira, M. A., Guth, B. E., Candeias, J. A., Ivey, C. \& other authors (1991). Enteropathogens associated with acute diarrheal disease in urban infants in Sao Paulo, Brazil. J Infect Dis 164, 331-337. Jenkins, C., Tembo, M., Chart, H., Cheasty, T., Willshaw, G. A., Phillips, A. D., Tompkins, D. \& Smith, H. (2006). Detection of enteroaggregative Escherichia coli in faecal samples from patients in the community with diarrhoea. J Med Microbiol 55, 1493-1497.

Jenkins, C., Chart, H., Willshaw, G. A., Cheasty, T. \& Tompkins, D. S. (2007). Association of putative pathogenicity genes with adherence characteristics and fimbrial genotypes in typical enteroaggregative Escherichia coli from patients with and without diarrhoea in the United Kingdom. Eur J Clin Microbiol Infect Dis 26, 901-906.

Jiang, Z. D., Okhuysen, P. C., Guo, D. C., He, R., King, T. M., DuPont, H. L. \& Milewicz, D. M. (2003). Genetic susceptibility to enteroaggregative Escherichia coli diarrhea: polymorphism in the interleukin-8 promotor region. J Infect Dis 188, 506-511.

Kaper, J. B., Nataro, J. P. \& Mobley, H. L. (2004). Pathogenic Escherichia coli. Nat Rev Microbiol 2, 123-140.

Keskimaki, M., Mattila, L., Peltola, H. \& Siitonen, A. (2000). Prevalence of diarrheagenic Escherichia coli in Finns with or without diarrhea during a round-the-world trip. J Clin Microbiol 38, 44254429.

Leiva, B., Lebbad, M., Winiecka-Krusnell, J., Altamirano, I., Tellez, A. \& Linder, E. (2005). Overdiagnosis of Entamoeba histolytica and Entamoeba dispar in Nicaragua: a microscopic, triage parasite panel and PCR study. Arch Med Res 37, 529-534.

Matar, G. M., Abdo, D., Khneisser, I., Youssef, M., Zouheiry, H., Abdelnour, G. \& Harakeh, H. S. (2002). The multiplex-PCR-based detection and genotyping of diarrhoeagenic Escherichia coli in diarrhoeal stools. Ann Trop Med Parasitol 96, 317-324.

Mayatepek, E., Seebass, E., Hingst, V., Kroeger, A. \& Sonntag, H. G. (1993). Prevalence of enteropathogenic and enterotoxigenic Escherichia coli in children with and without diarrhoea in Esteli, Nicaragua. J Diarrhoeal Dis Res 11, 169-171.

MINSA-NIC (2004). Boletín Epidemiológico Ministerio de Salud, Nicaragua. http://www.minsa.gob.ni/vigepi/html/boletin/2004/semana47/ editorial47.pdf.

Nataro, J. P. \& Kaper, J. B. (1998). Diarrheagenic Escherichia coli. Clin Microbiol Rev 11, 142-201.

Nataro, J. P., Mai, V., Johnson, J., Blackwelder, W. C., Heimer, R., Tirrell, S., Edberg, S. C., Braden, C. R., Glenn Morris, J., Jr \& Hirshon, J. M. (2006). Diarrheagenic Escherichia coli infection in Baltimore, Maryland, and New Haven, Connecticut. Clin Infect Dis 43, 402-407.

Nguyen, T. V., Le Van, P., Le Huy, C., Gia, K. N. \& Weintraub, A. (2005). Detection and characterization of diarrheagenic Escherichia coli from young children in Hanoi, Vietnam. J Clin Microbiol 43, 755760.

Nishikawa, Y., Zhou, Z., Hase, A., Ogasawara, J., Kitase, T., Abe, N., Nakamura, H., Wada, T., Ishii, E. \& Haruki, K. (2002). Diarrheagenic Escherichia coli isolated from stools of sporadic cases of diarrheal illness in Osaka City, Japan between 1997 and 2000: prevalence of enteroaggregative $E$. coli heat-stable enterotoxin 1 gene-possessing $E$. coli. Jpn J Infect Dis 55, 183-190.

Paniagua, M., Espinoza, F., Ringman, M., Reizenstein, E., Svennerholm, A. M. \& Hallander, H. (1997). Analysis of incidence of infection with enterotoxigenic Escherichia coli in a prospective cohort study of infant diarrhea in Nicaragua. J Clin Microbiol 35, 1404-1410.

Spano, L. C., Sadovsky, A. D., Segui, P. N., Saick, K. W., Kitagawa, S. M., Pereira, F. E., Fagundes-Neto, U. \& Scaletsky, I. C. (2008). Age-specific prevalence of diffusely adherent Escherichia coli in Brazilian children with acute diarrhoea. J Med Microbiol 57, 359-363.

Strockbine, N. A., Faruque, S. M., Kay, B. A., Haider, K., Alam, K., Alam, A. N., Tzipori, S. \& Wachsmuth, I. K. (1992). DNA probe analysis of diarrhoeagenic Escherichia coli: detection of EAF-positive 
isolates of traditional enteropathogenic E. coli serotypes among Bangladeshi paediatric diarrhoea patients. Mol Cell Probes 6, 93-99.

Tellez, A., Winiecka-Krusnell, J., Paniagua, M. \& Linder, E. (2003).

Antibodies in mother's milk protect children against giardiasis. Scand J Infect Dis 35, 322-325.
Vernacchio, L., Vezina, R. M., Mitchell, A. A., Lesko, S. M., Plaut, A. G. \& Acheson, D. W. (2006). Diarrhea in American infants and young children in the community setting: incidence, clinical presentation and microbiology. Pediatr Infect Dis J 25, 2-7.

WHO (2000). Handbook-Integrated Management of Childhood Illness, pp. 18-22. Geneva: World Health Organization. 